\section{CLINICAL CHARACTERISTICS OF 88 PATIENTS WITH} PUSTULOTIC ARTHRO-OSTEITIS (PAO) IN JAPAN

S. Tsujii ${ }^{1}$, Y. Ishihara ${ }^{2}$, H. Nishikawa ${ }^{3}$, Y. Taniguchi ${ }^{3}$, M. Kishimoto ${ }^{4} .{ }^{1}$ Department of Rheumatology and Allergology, National Hospital Organization, Osaka Minami Medical Center, Kawachinagano City, Osaka; ${ }^{2}$ Department of Orthopaedic Surgery, Kasumigaseki Urban Clinic, Tokyo; ${ }^{3}$ Department of Nephrology and Rheumatology, Kochi Medical School Hospital, Kochi; ${ }^{4}$ Immuno-Rheumatology Center, St. Luke's International Hospital, Tokyo, Japan

Background: The prevalence rate of PPP in Japan is somewhat as $0.13 \%{ }^{1)}$, accounting for $61 \%$ of cutaneous manifestations diseases associated with SAPHO syndrome ${ }^{2)}$. SAPHO syndrome ${ }^{3)}$ is not a new disease concept in which the cause of the disease has been clarified but is a name that classified diseased groups by collecting known diseases. On the other hand, PAO is a concept of disease that is a "proper subset" of SAPHO syndrome and is the smallest unit disease concept. Therefore, detailed information on PAO was sought.

Objectives: To examine the clinical features and treatment of PAO

Methods: We conducted a multicenter, non-intervention retrospective study of 88 PAO patients who were able to visit directly in 4 hospitals in Japan from January to June 2017. the criteria of "Sonozaki et al. 1981 4) " was used for PAO diagnosis. Evaluation items were clinical features, image/blood biochemical examination, treatment methods.

Results: The average age at the time of visit was 55.4 years old, palmoplantar pustulosis/PAO onset age was 44.4 years old, 49.3 years old, the onset pattern was skin leading type/simultaneous onset/joint advanced type (66.7/25.6/7.7\%). The clinical features were pain joints of $33.0 \%$ of the thoracic joints, $22.7 \%$ of the shoulder joints and $10.2 \%$ of the joints of the ankle joints, and the adhesion flame was the most abundant in the Achilles tendon at $21.4 \%$. ASDAS-CRP was 1.4 \pm 0.8 on average, breakdown was inactive disease $52.3 \%$, moderate $22.7 \%$, severe $22.7 \%$, very high disease activity $2.3 \%$, and insufficient disease activity remained in $25 \%$ of cases. Radiographic change showed in $81.8 \%$ of the sternum/the sternocostoclavicular joint, $33.0 \%$ of the spine, $31.0 \%$ of the sacroiliac joint (NY Ilor more), and $9.8 \%$ of the peripheral joint. MRI findings showed changes in intraosseous luminance in $76.9 \%$ around the sternum, $52.2 \%$ in the spine and $65.2 \%$ in the sacroiliac joint. Bone scintigraphy showed abnormal findings in the anterior chest $96.4 \%$, spine $23.6 \%$ and sacrum $30.9 \%$. Blood biochemical examination showed CRP $0.35 \pm 0.52 \mathrm{mg} / \mathrm{dl}$, RF positive rate $9.4 \%$, ACPA positive rate $5.1 \%$. First-line drugs (NSAIDs, biotin, anti-bacterial drugs) and second-line drugs (Iguratimod sulfasalazine MTX) were selected as therapeutic agents. For other treatments, $64.8 \%$ of topical therapy, $12.5 \%$ of phototherapy and $18.6 \%$ of tonsillectomy were performed.

Conclusions: In this study, we reported the clinical features, radiological findings and treatments in 88 Japanese patients with PAO in Japan. The treatment outcome for PAO in Japan is not sufficient, and it is necessary to try to elucidate further disease condition.

\section{REFERENCES:}

[1] Kubota K, Kamijima Y, Sato T, et al., Epidemiology of psoriasis and palmoplantar pustulosis: a nationwide study using the Japanese national claims database. BMJ Open. 2015 Jan 14;5(1)

[2] Okuno H, Watanuki M, Kuwahara $\mathrm{Y}$, et al., Clinical features and radiological findings of 67 patients with SAPHO syndrome. Mod Rheumatol. 2017 Sep 21:1-6.

3)

Chamot AM, Benhamou CL, Kahn MF, et al. Acne-pustulosis-hyperostosis-osteitis syndrome. Results of a national survey. 85 cases. Rev Rhum Mal Osteoartic. 1987 Mar;54(3):187-96. French.

[4] Sonozaki $\mathrm{H}$, Mitsui $\mathrm{H}$, Miyanaga $\mathrm{Y}$, et al. Clinical features of 53 cases with pustulotic arthro-osteitis. Ann Rheum Dis. 1981 Dec;40(6):547-53.

Acknowledgements: None

Disclosure of Interest: None declared

DOI: 10.1136/annrheumdis-2018-eular.4323

\section{$\mathrm{AB} 0890$}

EFFICIENCY OF 8-YEAR EDUCATIONAL PROGRAMS FOR PRIMARY CONTACT PHYSICIANS IN DIAGNOSIS AND TREATMENT OF AXIAL SPONDILOARTHRITIS IN KAZAN

S. Lapshina ${ }^{1}$, L. Myasoutova², R. Mukhina'2. ${ }^{1} 49$ Butlerov street, Kazan State Medical University, ${ }^{2}$ Clinicl Hospital \# 7, Kazan, Russian Federation

Background: In recent years, there have been cardinal changes in terminology, understanding of pathogenesis of axial spondylitis (AxsSpA) and ankylosing spondylitis (AS), early diagnosis has improved. An important role is played by the level of awareness of primary care physicians in the early diagnosis of AxsSpA and AS

Objectives: To evaluate the effectiveness of educational activities for primary contact physicians in AxsSpA (including AS) diagnostics for a long time.

Methods: From 2010 to the present time, educational activities are conducted for primary care physicians in diagnostics and tactics of managing patients with AS with discussion of the criteria for inflammatory back pain, options for onset and the algorithm for diagnosis and examination of patients with AxsSpA for primary contact physicians in Kazan. Since 2014, educational modules have been integrated into the system of continuing education of doctors. Assessment of the results of educational schools was carried out according to the analysis of reports of outpatient admission to rheumatologist of the City Rheumatological Centre in Kazan (Clinical Hospital \# 7) and the analysis of medical records of patients sent to a rheumatologist in 2009 (base year) in comparison with 2010-2017 in the process of schools.

Results: In the process of conducting schools (2010-2017) the number of patients with AxsSpA and AS significantly increased for the first time this year. In 2010-2011, the number of patients almost doubled (575 pts in 2010, 683 pts in 2011) compared to 2009 (378 pts). The second sharp increase in the number of patients was observed in 2016 (1178 pts) and in 2017 (1298 pts).

The same dynamics was observed for AxsSpA patients (including AS) who applied for the first time to rheumatologist with a significant increase in patients in 2010-2011 (2009-118 pts, 2010-190 pts, 2011-204 pts) and in 2016-506 pts, 2017 year -711 patients

"Peak" increase in the number of patients in 2010-2011 can be explained by the beginning of educational activities for doctors; in 2016-2017 - an increase in the number of activities (including remote ones), the amount of information, increased availability of MRI examinations for patients with AxsSpA

Primary care physicians were more likely to refer patients with suspected AxsSpA or diagnosed AS, the percentage of discrepancies between diagnoses (referral and rheumatology) decreased from $78 \%$ in 2009 to $18.1 \%$ in $2011,8.9 \%$ in 2013 , $2.1 \%$ in 2015 and $3.3 \%$ in 2017.

The number of patients coming from the primary contact physician to rheumatologist with the required volume of examination (description of back pain, laboratory tests, HLAB27 determination, radiographs and/or MRI) increased significantly from $23.7 \%$ in 2009 to $87 \%$ in 2017 , which allows to verify diagnosis without repeated consultations.

Conclusions: Educational programs for primary care physicians (lectures, schools, remote programs) have great importance for the timely diagnosis of AxsSpA, reducing the number of consultations before the diagnosis and with the subsequent appointment of adequate therapy.

Disclosure of Interest: None declared

DOI: 10.1136/annrheumdis-2018-eular.5707

\section{AB0891 DISEASE ACTIVITY PREDICTS FUNCTIONAL IMPAIRMENT AND SPINAL MOBILITY IN AXIAL SPONDYLOARTHRITIS}

T. Williams $^{1}$, A. Wadeley ${ }^{2}$, C. Cavill ${ }^{1}$, M. Freeth ${ }^{1}$, J. Hole $^{1}$, R. Sengupta ${ }^{1}$. ${ }^{1}$ Rheumatology, Royal National Hospital for Rheumatic Diseases; ${ }^{2}$ College of Liberal Arts, Bath Spa University, Bath, UK

Background: Axial Spondyloarthritis (axSpA) is a chronic inflammatory disease, mainly affecting the spine and sacroiliac joints. This results in progressive spinal immobility and can result in a level of disability comparable to Rheumatoid Arthritis $^{1}$. The natural history of axSpA and relationships between active inflammation, 